\title{
Temperature and Deformation Changes in Anthracite Coal after
}

\author{
Methane Adsorption \\ Zeng-chao Feng ${ }^{\mathrm{a}^{*}}$, Ting-ting Cai ${ }^{\mathrm{a}}$, Dong Zhou ${ }^{\mathrm{a}}, \quad$ Dong Zhao ${ }^{\mathrm{b}}, \quad$ Yang-sheng Zhao ${ }^{\mathrm{a}}, \quad$ Chen Wang ${ }^{\mathrm{a}}$
}

\begin{abstract}
Micropores are the primary sites of methane adsorption in coal, and the heterogeneous mesostructures of coal create the non-uniform distribution of the micropores in coal. Using a thermal infrared imager, the temperature distribution on the surface of an anthracite sample during methane adsorption/desorption was tested in this paper, and a new method is advanced to calculate methane adsorption capacity in coal based on its temperature increment. The results confirm the strongly non-uniform distribution of methane adsorption in coal. A X-ray CT scan test demonstrates that the volumetric zones of coal sample with a strong methane adsorption capacity have a lower average density. In these regions, the clay minerals with developed micropores also have a strong methane adsorption capacity. During the coal skeleton deformation of methane adsorption, the high density is hard to be squeezed, while low density areas are likely to be squeezed. Therefore, the complexity density distribution in coal leads to the incompatibility of deformation, which make the direct determination of regional uptake a challenge; From the SEM micrographs of the same coal sample with different densities determined by the X-ray CT scan, the mesostructures of cell cavity pores with non-compact packing of the clay minerals appear to be the primary sites of methane adsorption in coal, and the telocollinite with fewer pores has a lower methane adsorption capacity.
\end{abstract}

Keywords: Cell cavity structure; Vitrinite; Meso deformation; SEM-EDS; Infrared thermal imager; X-ray CT

\section{Introduction}

Pores are the primary sites of methane adsorption in coal. From the distinction of the pore sizes in a porous adsorbent by Dubinin, the number and specific surface area of the micropores with a pore size less than $2 \mathrm{~nm}$ -1 - 


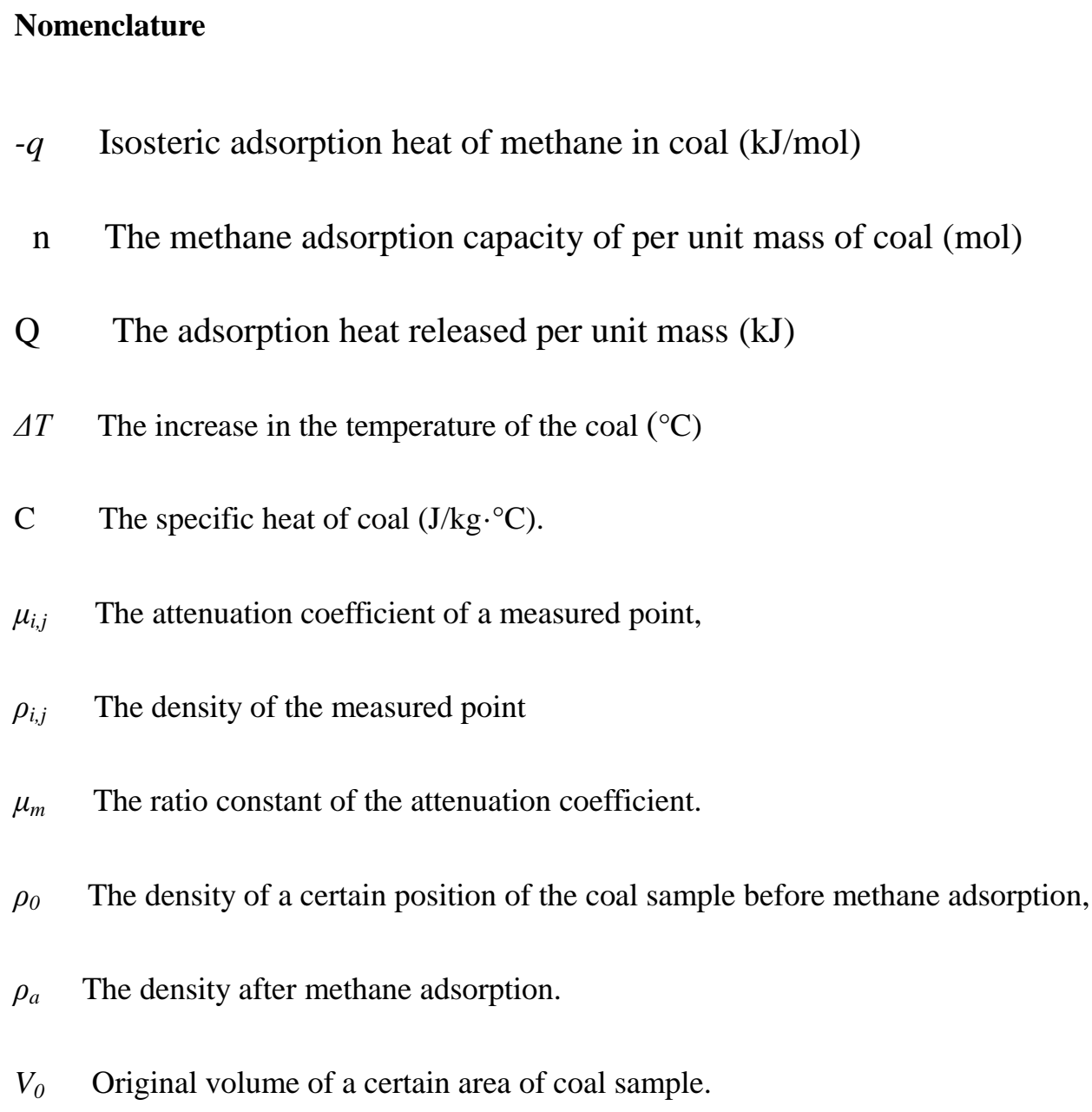

1 directly determine the adsorption capacity of coal. Past studies have evaluated the number and structure of the micropores by MIP (Mercury Intrusion Porosimetry) and $\mathrm{N}_{2}$ adsorption experiments. However, these studies did

3 not consider the changes in the pore structures during methane adsorption. Recently, X-ray CT (Computed 4 Tomography) scans have been widely used in the research into the mesostructures of coal [1-4]. Compared with 5 the methods of MIP and $\mathrm{N}_{2}$ adsorption, the methodology of X-ray CT scan has the advantage of studying the mesostructure deformation in coal during methane adsorption to infer the nature of the methane distribution in 7 coal. Karacan et al. have observed and evaluated the differences in gas migration and adsorption rate between 8 different categories of mesostructures using X-ray CT imaging technology, proposed that clay minerals in coal 9 have a high porosity and density, and pore structures in the coal matrix have higher gas storage capacity[5,6]. However, during the methane adsorption, the local deformation of coal not under confining stress could be 11 swelling or extrusion deformation [7]. Therefore, the evaluation of the methane adsorption capacity by the 
variation in the attenuation coefficient of X-ray CT is not sure yet.

SEM (Scanning Electron Microscopy) makes use of secondary electron signal imaging to observe the surface morphology of the sample, to infer material components [8], and to reveal the microstructure on the nanometre scale. Many scholars have studied the pore characteristics of coal from different angles via the SEM test, which has multiple advantages in the study of coal pore fissures, mineral matter, and microstructures $[9,10]$. Past studies have shown that adsorption heat is released during methane Carbon dioxide and other gases adsorption in coal, resulting in a rise in the coal temperature $[11,12]$. The temperature variation during methane adsorption offers a new means to evaluate the methane adsorption/desorption capacity of coal and can also be used as the basis for the prediction of dynamic geological disasters, such as coal seam gas outbursts $[13,14]$. The research performed by Chaback et al. [15] shows that methane adsorption in coal is a physical process with heat release, and the temperature variation of the coal is caused by creation of adsorption heat in the process of adsorption. Nodzenski [16] found that under the same conditions, the isosteric adsorption heat of coal and methane increased with the increase of coal metamorphism. If the isosteric heat of adsorption is higher, the adsorption capacity of the coal sample is greater. The experimental study performed by Guo et al. with embedded temperature sensor [17] shows that heat release in coal during $\mathrm{CO}_{2}$ adsorption is higher than methane, causing the temperature of coal to be increased by $10^{\circ} \mathrm{C}$ followed by the heat release from methane adsorption, and the heat release from nitrogen adsorption is the lowest. Infrared thermal imager can be used to make multi-point temperature measurements on the surface of an object through the induction of infrared radiation in a colour image display. The infrared thermal imager measurement is a noncontact measurement with many advantages, including fast response, wide range of temperature measurement, high sensitivity, and high space resolution [18]. Liu et al. [19] has successfully observed the temperature change in the coal adsorption/desorption process by using an infrared thermal imager. 
which mainly refers to the coal matrix, clay minerals and meso pores and fissures in this paper. A suitable

observation scale was selected based on the three evaluations (CT, SEM-EDS and infrared thermal imaging).

From the SEM-EDS test on the coal sample surface, the original mesostructures of coal can be observed. From the synchronous real-time measurements of X-ray CT and infrared thermal imaging on the same position in the methane adsorption/desorption process, the non-uniformity of mesostructure deformation and methane distribution in coal can be tested under different adsorption pressures. From the combination of the three tests, the deformation characteristics and adsorption capacity of different mesostructures in coal can be analysed, and the diversity of the methane adsorption and the deformation of coal is revealed.

\section{Infrared Thermal Imaging Test for Methane Adsorption of Coal}

\subsection{Preparation of coal sample}

The coal sample for testing is a type of anthracite and was obtained from the Sijiazhuang Coal Mine, Yangquan Coal Industry Group, as shown in Fig. 1. The meso coal sample (12 mm height, $8.5 \mathrm{~mm}$ diameter) was cored into the bedding plane. A cross-cut groove was made in the radial direction on the surface of the coal sample.

This groove was used as the mark line on the surface of coal sample in different positions. Next, the coal sample was cleaned and dried with oven no more than $60{ }^{\circ} \mathrm{C}$ for later use. The results from the measurement of proximate analysis and vitrinite reflectance of the anthracite coal are shown in Table 1.

\subsection{SEM and micro X-ray CT scanning test}

A JSM-7001F-type thermal field emission scanning electron microscope was used in this paper, with a scanning voltage of $5 \mathrm{kV}$ and a breadth of $10 \mathrm{~mm}$. The microscope could be used to observe the micro structure on the surface of coal on the micrometre scale. For X-ray CT scanning, a $\mu \mathrm{CT} 225 \mathrm{kVFCB}$ type high-precision micro X-ray CT test system was used [22]. A Uti380D-type high definition infrared thermal imager was used for the infrared scanning test for the methane adsorption of coal, which could be used to detect infrared radiation with a wavelength of $8-14 \mu \mathrm{m}$ and with a thermal sensitivity of $0.08{ }^{\circ} \mathrm{C}$. The test principle is shown in Fig. 2 . The test 
system consisted of the following: A pressure cylinder made of titanium alloy material was used for the placement of the coal sample and gas storage and to carry out the adsorption. The test showed that the cylinder had good gas tightness. A transparent infrared glass window was installed on the top of the cylinder and has high infrared transmittance up to more than $95 \%$. A rotation platform was used to fix the pressure cylinder. A digital pressure gauge was used to indicate the pressure of the methane gas in a pressure cylinder. Other auxiliary devices, such as a needle valve, a methane gas storage bottle, and a fixed beam of the infrared thermal imager, and the related tubes and lines were also used. The coal sample was placed in the pressure cylinder vertically and was wrapped with thermal insulation in the axial direction to maintain thermal insulation during the adsorption process. The lower end of the coal sample was supported by a light spring to retain the coal placement during the test. The surface of the upper end was placed in close contact with the highly transparent infrared glass window to aid in infrared thermal imager measurement of thermal radiation. The radiographic source Micro X-ray CT passing through would emit X-rays, and flat panel detector could be used to collect the scanning data. The test device was fixed on the rotation platform of the X-ray CT system, which rotated at a constant speed (the same as the speed used during scanning) to ensure that the coal sample was scanned fully. The displacement of the motion controller for the Micro X-ray CT could be controlled at the micrometre level, and it could ensure that the test device does not shift in any direction during the entire scanning process to ensure the accuracy of the test. The test steps were as follows:

1) The coal sample underwent vacuum treatment in the pressure cylinder. A 2XZ-0.5-type double rotary vane vacuum pump was used to take the coal sample to a vacuum less than $0.6 \mathrm{~Pa}$ for more than $1 \mathrm{~h}$ to ensure that no other gas was present in the coal sample and the pressure cylinder. Manually adjusting focal length of infrared thermal imager caused a radial cross cutting groove on the coal sample to be displayed clearly on the screen of the infrared thermal imager. Then, a photograph of the infrared thermal image and a X-ray CT scan was obtained before the adsorption. 
thermal imager was used to take continuous photos of the coal sample during methane adsorption, and record the

adsorption time until the infrared thermal image remained unchanged. The adsorption was maintained at a constant pressure for $12 \mathrm{~h}$ to ensure that the X-ray CT scan was performed at the adsorption state at $0.6 \mathrm{MPa}$ after the adsorption was balanced. Then, the valve was opened, thereby causing a pressure drop to atmospheric.

Meanwhile, the infrared thermal imager was used to take continuous photographs of the desorption process of the coal sample and record the desorption time until the infrared thermal image was basically unchanged.

3) The steps of 1) and 2) were repeated. Infrared thermal imaging and X-ray CT scanning were performed for adsorption/desorption process of the coal sample at 1.2 MPa.

\section{Methods}

\subsection{The relationship between temperature and adsorption}

The temperature rise of the coal during methane adsorption is caused by the adsorption heat of the coal surface and the methane molecules, which is closely related to the amount of methane adsorption in coal, namely,

$$
Q=-q n
$$

Assume that the methane adsorption in coal is carried out under adiabatic conditions. As the heat released has no other physical effect but to increase the temperature of the coal, from Eq. (1),

$$
n=\frac{\Delta T \cdot C}{\varepsilon}
$$

Thus, assuming that the different locations of the coal-specific heat capacity and the isosteric heat of adsorption are constant values, the temperature rise for each coal unit is proportional to its methane adsorption. The higher the rise in temperature, the larger the amount of methane adsorbed.

\subsection{The deformation calculation method based on X-ray CT scan}

$\mathrm{X}$-ray $\mathrm{CT}$ is used to scan the section of the object to be measured by using X-rays to obtain a section image that indicates a change in material density. The attenuation coefficient is the variation in the X-ray intensity when 
crossing a section of the measured object, and the relationship between this attenuation coefficient and the density is [23]:

(1)

$$
\mu_{i, j}=\mu_{m} \rho_{i, j}
$$

The swelling deformation of coal occurred during methane adsorption, resulting in the decrease in the coal density. Therefore, the amount of swelling deformation in the coal can be obtained from its density variation.

(1)

$$
\text { If the mass change caused by methane adsorption of the coal is ignored, the following can be obtained: }
$$

$$
\rho_{0} v_{0}=\rho\left(v_{0}+\Delta v\right)
$$

Based on the volumetric strain formula, the following expression is obtained.

$$
\varepsilon=\frac{\Delta v}{v_{0}}
$$

In Eq. 3, $\Delta \mathrm{V}>0$ means expansion deformation, and $\Delta \mathrm{V}<0$ means extrusion deformation. If Eqs. (1) and (3) are inserted into Eq. (2), the following can be obtained:

$$
\varepsilon=1-\frac{\mu_{0}}{\mu}
$$

Where $\mu_{0}$ refers to original attenuation coefficient of a certain position of the coal sample. The parameter $\mu$ refers to the attenuation coefficient after methane adsorption. Eq. (4) is based on the computed deformation $\varepsilon$ at different positions of the coal sample before and after methane adsorption. If $\varepsilon>0$, extrusion deformation occurred in this position. Otherwise, expansion deformation occurred in this position.

\section{Infrared Imaging Characteristics of Methane Adsorption of Coal}

Coal surface temperature arrays at different adsorption/desorption times from the infrared thermal imaging were extracted to compare with the coal surface temperature array before adsorption. A pseudo-colour display in the same colour range was used as the basis for obtaining the change in the coal surface temperature over time under different adsorption pressures. Each pixel of these images corresponds to the absolute size of the coal sample surface $35.4 \times 35.4 \mu \mathrm{m}^{2}$. 
pressures is shown in Fig. 3. With the increase in the adsorption time, the environmental temperature of the coal

sample remained unchanged, and the coal surface temperature rose significantly. During the desorption process, the coal surface temperature decreased. During adsorption/desorption, the coal surface temperature change was non-uniform. The temperature rise during the methane adsorption of the coal first occurred in the right middle and upper area. During desorption, the temperature decrease occurred mainly in the same position. If the adsorption pressure was higher, the temperature changed more significantly. According to 2.1 calculation method, Fig. 3 shows that, during the methane adsorption, the right middle region of the coal surface has a larger temperature rise than the adjacent areas, which can be confirmed by its greater methane adsorption. During desorption, desorption of a large amount of methane occurred in this position, thereby causing a more significant temperature decrease.

\section{Absorption/Desorption Characteristics of Coals with Different}

\section{Microstructures}

The difference in temperature between adsorption and desorption in a rectangular area of the upper right portion of the coal sample $(4.5 \mathrm{~mm} \times 2.2 \mathrm{~mm})$ is large. This area was selected for X-ray CT scanning, SEM, and analysis of the temperature change during adsorption/desorption (Fig. 4). SEM results show that the coal sample consists mainly of a vitrinite coal matrix and clay minerals. The telocollinite structure is dense, and pore development is poor. Structural vitrinite contains cell cavity pores and a mesofracture structure on different scales.

The distribution of the cell cavity pores is strip-shaped in a certain direction. Clay minerals show bedded crystallization and are packed in a cell cavity pore of the coal matrix or a mesofracture. An energy spectrum test (Table 2) was used. The peak value of the silicon aluminium occurs in this part of the spectrum. This result indicates that its main component is aluminium silicate.

A 4.5-mm-wide and 0.075-mm-high rectangular area was selected. ten representative areas with significant characteristics were selected in different radial places on the rectangular. The size of each area was $0.1 \mathrm{~mm} \times$ 

mesostructures, the area was divided into 4 categories.

The first category was a cell cavity pore with non-compact packing of the clay minerals (as the A, B, C, and D areas in Fig. 6). Many 1-20- $\mu \mathrm{m}$ plant cell cavity tissues are preserved in the coal formation process and partially filled with clay minerals. Due to the squeezing and friction effects of the geological structure, cleats and microfractures (A, B) and breccia (C, D) pores are formed. Due to non-compact packing or long-term erosion, many intercrystalline pores, interlayer holes, and intergranular pores are present in the filled clay minerals.

The second category was a cell cavity structure with compact packing of the clay minerals. The E area in Fig. 6 was different from the cell cavity with non-compact packing of clay minerals because this structure was densely filled with clay minerals, and the cell cavity structure was completely preserved. From the SEM image at a magnification of 1000 times, the clay mineral layer is a flake or granular crystal with fewer intercrystalline pores and poor connectivity between cell cavities. compact and uniform, with almost no meso-scale pore structure at a magnification of 8000 times.

The fourth category is a mesofracture filled with clay minerals at different packing degrees. As shown in the $\mathrm{H}$, I, and $\mathrm{J}$ areas in Fig. 6, in mesofractures (width of $0-20 \mu \mathrm{m}$ ), clay minerals are partially or fully filled, thereby forming clay mineral ribbons across various scales.

Temperature change curves of different mesostructures in the adsorption/desorption process are shown in Fig. 6. During methane adsorption, the temperature rise in the non-compact-packing cell cavity pore (area B) and the fracture structure (area I) with stronger methane adsorption capacity is faster (within $0-10 \mathrm{~s}$ ), reaching $3.51^{\circ} \mathrm{C}$ under an adsorption pressure of $1.2 \mathrm{MPa}$. Within $10-75 \mathrm{~s}$, due to heat transfer and heat dissipation, the temperature decreased significantly. The temperature rise in a compact-packing cell cavity pore (area $\mathrm{H})$ and telocollinite (area F) with a stronger methane adsorption capacity is slower, reaching $2.7^{\circ} \mathrm{C}$ within $0-20 \mathrm{~s}$. The 
temperature rises slowly to $2.7^{\circ} \mathrm{C}$ in $0-20 \mathrm{~s}$ of adsorption time. The temperature rise in the compact-packing cell

cavity pore (area E) and the telocollinite (area G) with stronger methane adsorption capacity is slowest, reaching $2.5^{\circ} \mathrm{C}$ within $0-43 \mathrm{~s}$. In the desorption process, the region (area B, area I) with the strongest adsorption capacity is preferentially desorbed with the fastest temperature decrease. The region (area E, area F) with the lowest adsorption capacity is preferentially desorbed with the slowest temperature decrease. Because of heat transfer, the temperature of different adsorption areas tends to be balanced for a long time in both adsorption and desorption processes.

From the comparison of Fig. 4-6, due to the restrictions of the image resolution, only the density of the coal in a certain area can be estimated by the X-ray $\mathrm{CT}$ attenuation coefficient, while the mesostructure of coal, especially the micropores, cannot be described. From Fig. 4, the B area corresponds to the clay mineral cluster with an attenuation coefficient far higher than other areas. Meanwhile, a higher temperature rise than in the adjacent areas occurs during the methane adsorption. In Fig. 5, the B area has developed pore structures, suggesting that the porous clay minerals in the coal have a large methane adsorption capacity. Compared with the area $\mathrm{B}$, the area $\mathrm{C}$ is also a porous area with a lower attenuation coefficient. Area $\mathrm{C}$ has a temperature rise similar to the area B during methane adsorption, which suggests that its methane adsorption capacity is similar to the area B. As the position of the area A is near the edge of the sample, its temperature rise may be affected by the heat transformation; therefore, it is not discussed in this study. From the comparison of B, C, and D areas, the porous coal matrix and small clay mineral particles have similar methane adsorption capacities.

From comparison of $\mathrm{C}, \mathrm{D}$, and $\mathrm{F}$ areas with similar attenuation coefficients, the $\mathrm{C}, \mathrm{D}$ areas are located in the mineral ribbons containing clay, with clay mineral particles and developed pores, and the $\mathrm{F}$ area is mainly the telocollinite. During methane adsorption, the methane adsorption capacity of the C, D areas is larger than the methane adsorption capacity of the F area, indicating that the micropores are the main sites of methane adsorption.

\section{Deformation Characteristics of Different Mesostructures of Coal}


The X-ray CT scan and deformation characteristics of different mesostructures of coal during methane

adsorption are summarized in Table 3 . The cell cavity pores non-compactly filled with clay minerals with high methane adsorption capacity (A, B, C, D) can occur with either swelling deformation or extrusion deformation. Even in some areas, the transition from the extrusion to the swelling deformation occurs with the increase in adsorption capacity. The non-coordinated deformation is the main reason for the irreversible damage in coal.

With the clay minerals non-compactly filled, the mesofractures in areas I and $\mathrm{J}$ in Fig.5 show extrusion deformation due to the swelling deformation of the surrounding coal during methane adsorption. The mesofracture with clay minerals non-compactly filled in area $\mathrm{H}$ has a smaller methane adsorption capacity than the mesofracture with the clay minerals non-compactly filled. However, swelling deformation occurs during methane deformation at its higher extent.

The telocollinite (the areas F and G) is a major component of the coal, but it is not the main site of methane adsorption from the thermal imaging. Either swelling deformation or extrusion deformation can occur during methane adsorption. Even in some areas, the transition from the extrusion to the swelling deformation occurs with the increase in adsorption capacity.

From the comparison of the deformation and the temperature rise in areas B and E, under the pressure of 0.6 $\mathrm{MPa}$, the swelling deformation of $\mathrm{E}$ is 1.297 times the swelling deformation of area $\mathrm{B}$, while the temperature rise in $\mathrm{E}$ is 0.389 times the temperature rise in area B. From Eq. (2), the methane content of area B is 2.75 times the methane content of area $\mathrm{E}$. Under the pressure of $1.2 \mathrm{MPa}$, the swelling deformation of $\mathrm{F}$ is 5.35 times the swelling deformation of area B, while the methane content of area B is 2.29 times the methane content of area $\mathrm{E}$ from the temperature variation. Therefore, it make the direct determination of regional uptake according to the data obtained from the X-ray CT scan a challenge, and this inference occasionally produces incorrect results.

Expansion deformation from the methane adsorption of coal occurred mainly in high-density areas that contain clay minerals. Intercalation adsorption of methane in the clay minerals will cause an increase in the crystal 
layer spacing of clay minerals [24-26], thereby leading to expansion deformation. A certain degree of extrusion to

the adjacent low-density vitrinite coal matrix and pore fracture was observed, causing damage to the coal. The localized density changes in the coal depend on the complex mesostructures and their deformation, which cannot be the evidence of the methane content.

\section{Conclusions}

With the combination of X-ray CT scanning, SEM-EDS, infrared imaging, and a variety of testing methods, the temperature change and the deformation law for the microstructure in the process of coal adsorption and methane desorption were studied. The study's conclusions are the following:

1 ) Methane adsorption at different positions in the coal had nonuniform adsorption characteristics. During methane adsorption/desorption, the temperature rise/decrease was more obvious in the position where methane adsorption was higher in the coal than in adjacent areas.

2 ) The methane adsorption capacity of coal in different positions was closely related to its mesostructure. In the vitrinite in the coal, a large number of breccia holes and cracked coal structures with different sizes of cell cavity filled with clay minerals, and the mesofracture had a very strong methane storage capacity, and these properties are sensitive to the temperature during adsorption/desorption. In compact telocollinite and compact-packing cracks and cell cavity structures, the pore structure was developed more poorly, and the methane adsorption capacity was weaker. The temperature change was lower during adsorption/desorption.

3) Methane adsorption leads to significant deformation of the coal mesostructure. The deformation includes expansion and extrusion deformation. If the adsorption pressure was high, the deformation of the mesostructure increased in significance. Expansion deformation of the coal during methane adsorption occurred mainly in the area containing high-density clay minerals, where a significant squeezing effect was observed on the low-density vitrinite coal matrix and pore and crack structure in the coal.

4) During methane adsorption, the localized density changes in the coal depend on the complex 
mesostructures and their deformation. The localized density changes in the coal have nothing to do with the

2 methane adsorption capacity. Therefore, it is extremely unreliable to infer the distribution of methane in coal

3 according to the data obtained from X-ray CT scan.

\section{Acknowledgments}

The authors are grateful to the National Science Foundation of China for financial support (21373146,

\section{References}

8 [1] Liu S, Sang S, Wang G, Ma J, Wang X, Wang W, et al. FIB-SEM and X-ray CT characterization of interconnected pores in high-rank coal formed from regional metamorphism. Journal of Petroleum Science and Engineering. 2017; 148:21-31.

[2] Heriawan MN, Koike K. Coal quality related to microfractures identified by CT image analysis. International Journal of Coal Geology. 2015; 140:97-110. processes. International Journal of Coal Geology. 2011; 88:152-62. multi-spectrum synchrotron X-ray CT. Fuel. 2013; 106:219-25. 

gasification reactivity. Fuel. 2005; 84(10):6. dioxide. Journal of Natural Gas Science and Engineering. 2015; 25:242-52. high-rank coal formed from regional metamorphism. Journal of Petroleum Science and Engineering. 2017; 148:21-31.

[14] Guo L, Yu Q, Jiang C, et al. Testing study on the variation of coal temperature during the process of coal and gas outburst.

[17] Guo L, Yu Q, Wang K. Experimental study on change in coal temperature during adsorbing gas. Chinese Journal of Rock Mechanics \& Engineering. 2000; 29:287-296.

[18] Fan J, Yang J. Analysis of the development trend of infrared imaging detection technology. Infrared \& Laser Engineering. 2012; 41:3145-3153.

[19] Liu J, Wang C, He X, Li S. Infrared measurement of temperature field in coal gas desorption. International Journal of Mining Science and Technology. 2014; 24:57-61. 
[22] Yu Y, Hu Y, Liang W, et al. Micro-CT experimental research of lean coal thermal cracking laws. Journal of China Coal Society. 2010, 35:1696-1700.

3 [23] ASTM E1935-1997 (Reapproved 2003), Standard Test Method for Calibrating and Measuring X-ray CT Density, 1-5.

4 [24] Ji L, Qiu J, Xia Y, et al. Micro-pore characteristics and methane adsorption properties and methane adsorption properties of common clay minerals by electron microscope scanning. Acta Petrolei Sinica. 2012; 33:249-56.

6 [25] Ji L, Zhang T, Kitty L, et al. Experimental investigation of main controls to methane adsorption in clay-rich rocks. Applied Geochemistry.2012; 27:2533-2545.

[26] Zhou Q, Lu X, Liu X, et al. Hydration of methane intercalated in Nasmectites with distinct layer charge: Insights from molecular simulations. Journal of Colloid \& Interface Science. 2011; 355: 237-242. 
Table 1 Proximate analysis and Vitrinite reflectance of the Anthracite Coal

\begin{tabular}{|c|c|c|c|c|c|c|}
\hline \multirow[b]{2}{*}{ Rank } & \multirow{2}{*}{$\begin{array}{c}\text { Weight } \\
(\mathrm{g})\end{array}$} & \multirow{2}{*}{$\begin{array}{c}\text { Maximum reflectance } \\
\text { of vitrinite } \\
(\%)\end{array}$} & \multicolumn{4}{|c|}{ Proximate analysis } \\
\hline & & & $\begin{array}{c}\text { Moisture } \\
(\%)\end{array}$ & $\begin{array}{c}\text { Ash yield } \\
(\%)\end{array}$ & $\begin{array}{c}\text { Volatile matter } \\
\qquad(\%)\end{array}$ & $\begin{array}{c}\text { Fixed Carbon } \\
(\%)\end{array}$ \\
\hline Anthracite & 0.966 & 2.45 & 1.39 & 13.13 & 7.12 & 78.36 \\
\hline
\end{tabular}

Table 2 Energy spectrum analysis result of coal surface

\begin{tabular}{cccc|cccc}
\hline Region & \multicolumn{3}{c|}{ Vitrinite matrix } & \multicolumn{4}{c}{ Clay minerals } \\
\hline EL & $\mathrm{C}$ & $\mathrm{O}$ & $\mathrm{S}$ & $\mathrm{C}$ & $\mathrm{O}$ & $\mathrm{Si}$ & $\mathrm{Al}$ \\
Norm. C [wt.\%] & 86.36 & 13.22 & 0.42 & 45.67 & 34.86 & 10.54 & 8.93 \\
\hline
\end{tabular}

Table 3 Deformation characteristics of methane adsorption in different meso structure

\begin{tabular}{|c|c|c|c|c|c|c|c|c|}
\hline \multirow[b]{2}{*}{ Mesostructural Region } & & \multicolumn{2}{|l|}{$0 \mathrm{MPa}$} & \multicolumn{2}{|l|}{$0.6 \mathrm{MPa}$} & \multicolumn{3}{|c|}{$1.2 \mathrm{MPa}$} \\
\hline & & $\mu$ & $\varepsilon(\%)$ & $\begin{array}{c}\text { Type of } \\
\text { deformation }\end{array}$ & $\Delta T_{\mathrm{Ads}}^{9 \mathrm{~s}}$ & $\varepsilon(\%)$ & $\begin{array}{c}\text { Type of } \\
\text { deformation }\end{array}$ & $\Delta T_{\mathrm{Ads}}{ }^{9 \mathrm{~s}}$ \\
\hline \multirow{4}{*}{$\begin{array}{c}\text { A cell cavity pore with } \\
\text { noncompact packing of clay } \\
\text { minerals }\end{array}$} & A & 0.005958 & 23.1361 & Extrusion & 2.3057 & 16.7562 & Extrusion & 3.0066 \\
\hline & $\mathrm{B}$ & 0.010984 & -1.98730 & Swelling & 1.8217 & -5.28148 & Swelling & 3.3930 \\
\hline & $\mathrm{C}$ & 0.007078 & 2.87350 & Extrusion & 2.9273 & 3.22974 & Extrusion & 3.3201 \\
\hline & $\mathrm{D}$ & 0.006098 & 2.99946 & Extrusion & 3.1632 & -1.75511 & Swelling & 3.4497 \\
\hline $\begin{array}{c}\text { A cell cavity structure with } \\
\text { compact packing of clay minerals }\end{array}$ & $\mathrm{E}$ & 0.815000 & -25.7660 & Swelling & 0.7071 & 8.24077 & Extrusion & 1.3911 \\
\hline \multirow{2}{*}{ A telocollinite coal matrix } & $\mathrm{F}$ & 0.007134 & -7.84819 & Swelling & 0.5835 & -28.2484 & Swelling & 1.4831 \\
\hline & $\mathrm{G}$ & 0.007706 & -2.13738 & Swelling & 1.1994 & 0.08003 & Extrusion & 2.2567 \\
\hline Filled crack with clay minerals & $\mathrm{H}$ & 0.011195 & -3.63453 & Swelling & 1.0312 & -6.90756 & Swelling & 2.3302 \\
\hline \multirow{2}{*}{$\begin{array}{l}\text { Filled crack with compact } \\
\text { packing of clay minerals }\end{array}$} & I & 0.007699 & 2.88890 & Extrusion & 1.6787 & 8.33720 & Extrusion & 2.9313 \\
\hline & J & 0.005491 & 13.7046 & Extrusion & 3.0598 & 16.3615 & Extrusion & 3.2086 \\
\hline
\end{tabular}



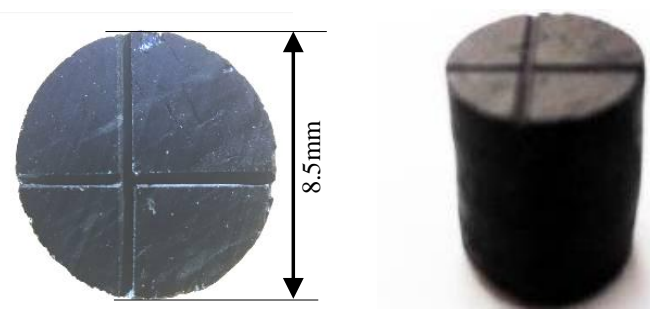

Fig. 1 Coal sample for test

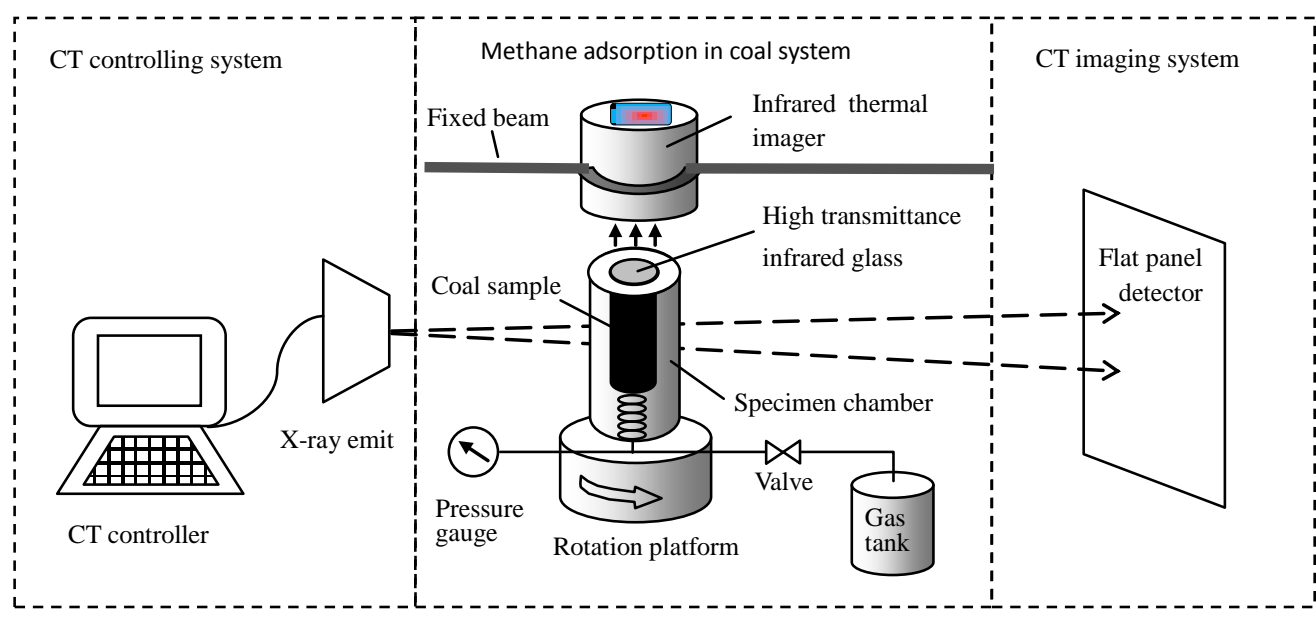

Fig. 2 Test principle of methane adsorption of coal by Micro CT and infrared thermal imager

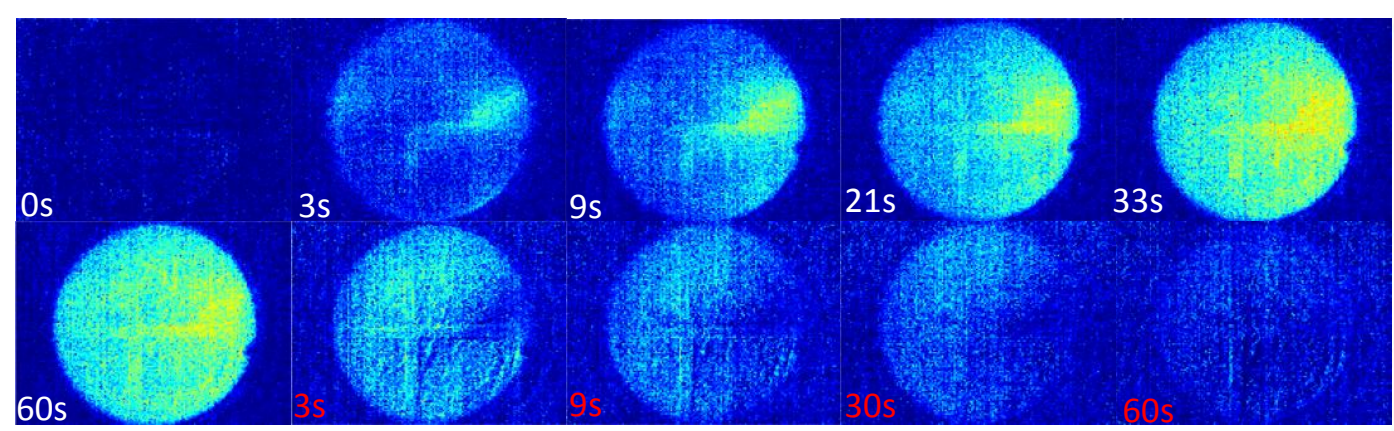

(a) Adsorption pressure: $0.6 \mathrm{MPa}$

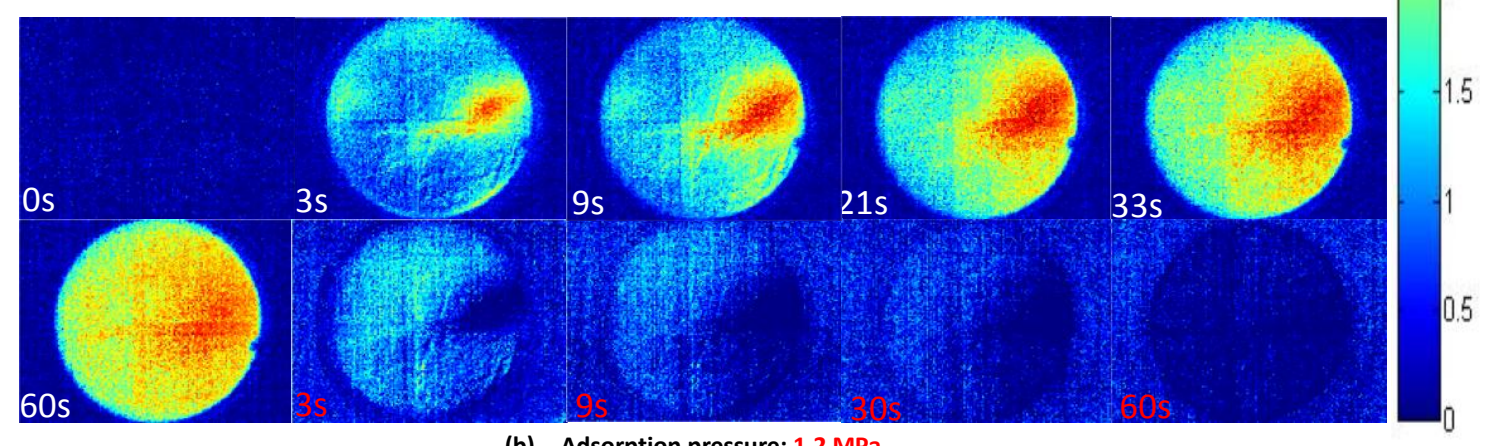

(b) Adsorption pressure: $1.2 \mathrm{MPa}$

Fig. 3 Temperature change of coal adsorption/desorption methane captured by infrared thermal imager $\left({ }^{\circ} \mathrm{C}\right)$ (Adsorption time is in white, desorption time is in red) 


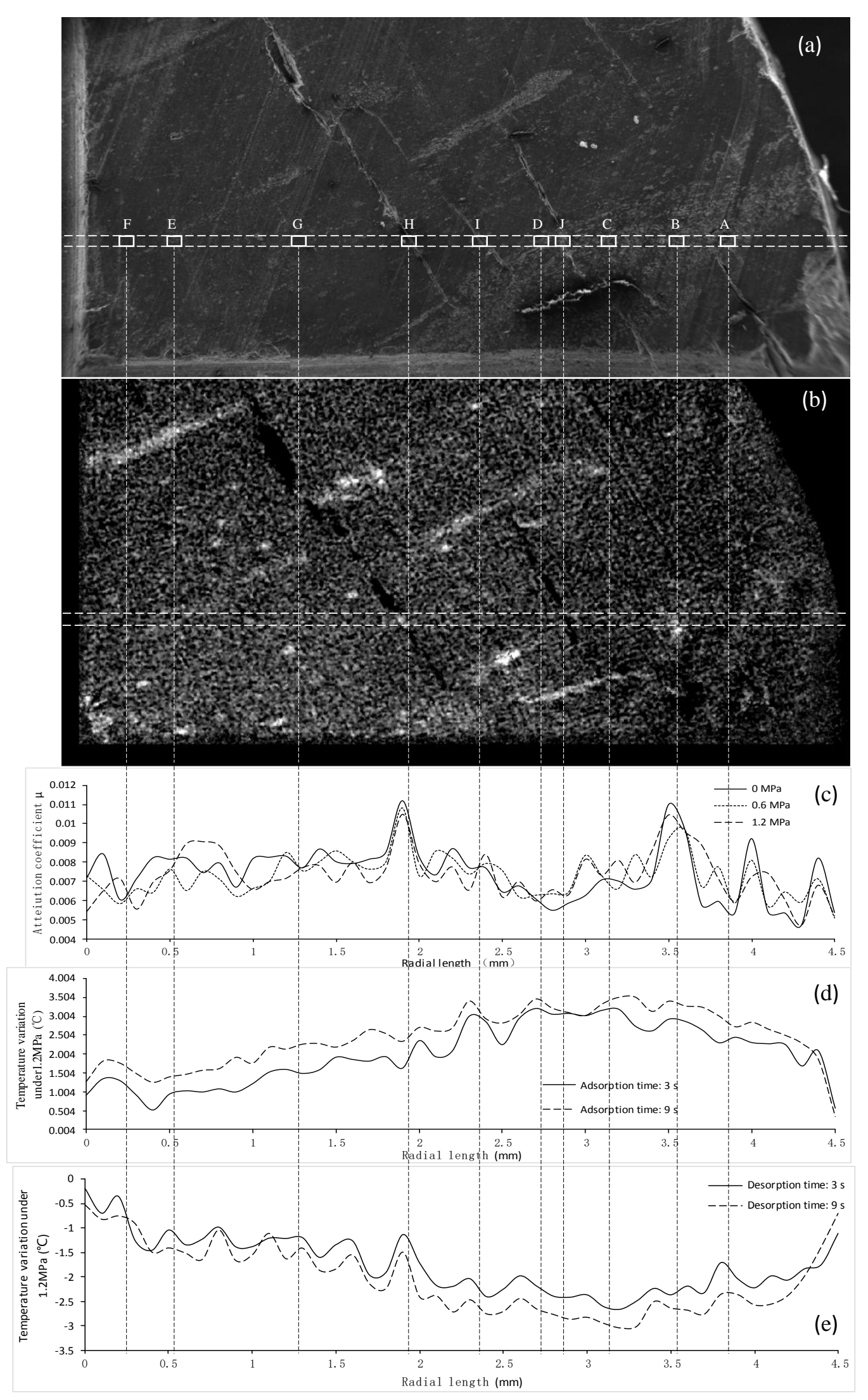

Fig. 4 CT and SEM image of coal and temperature distribution of methane adsorption/desorption ( $a$, SEM micrographs of coal; $b, \mathrm{X}$-ray CT image of coal $c$, Attenuation coefficient of rectangular regions; $d$, Temperature variation of rectangular regions during methane adsorption; $e$, Temperature variation of rectangular regions during methane desorption) 


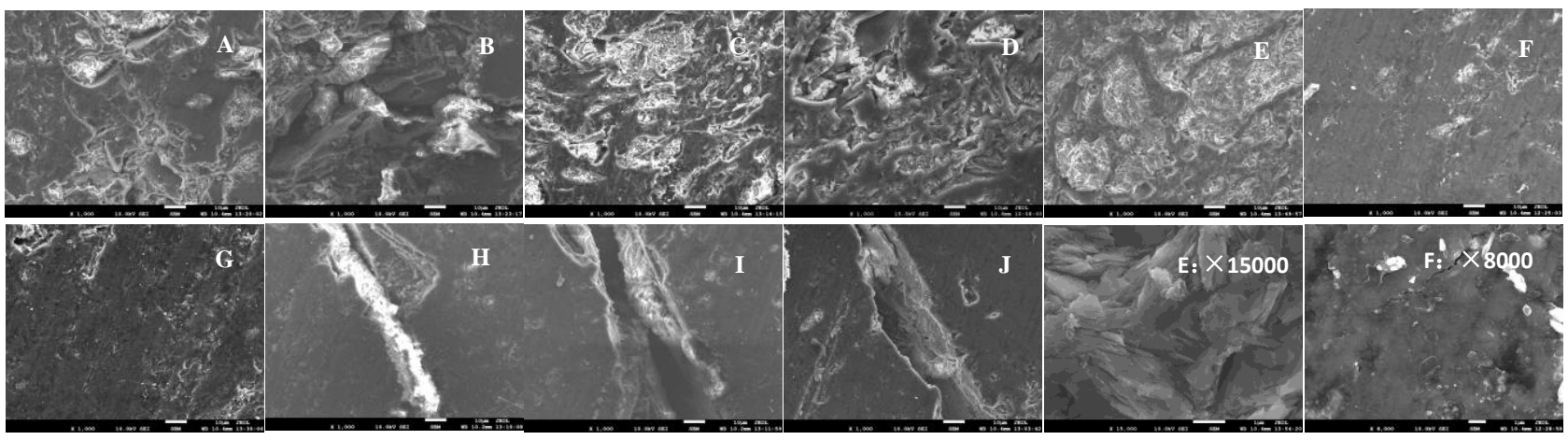

Fig. 5. SEM micrographs of mesostructure of coal sample shown in Fig.4

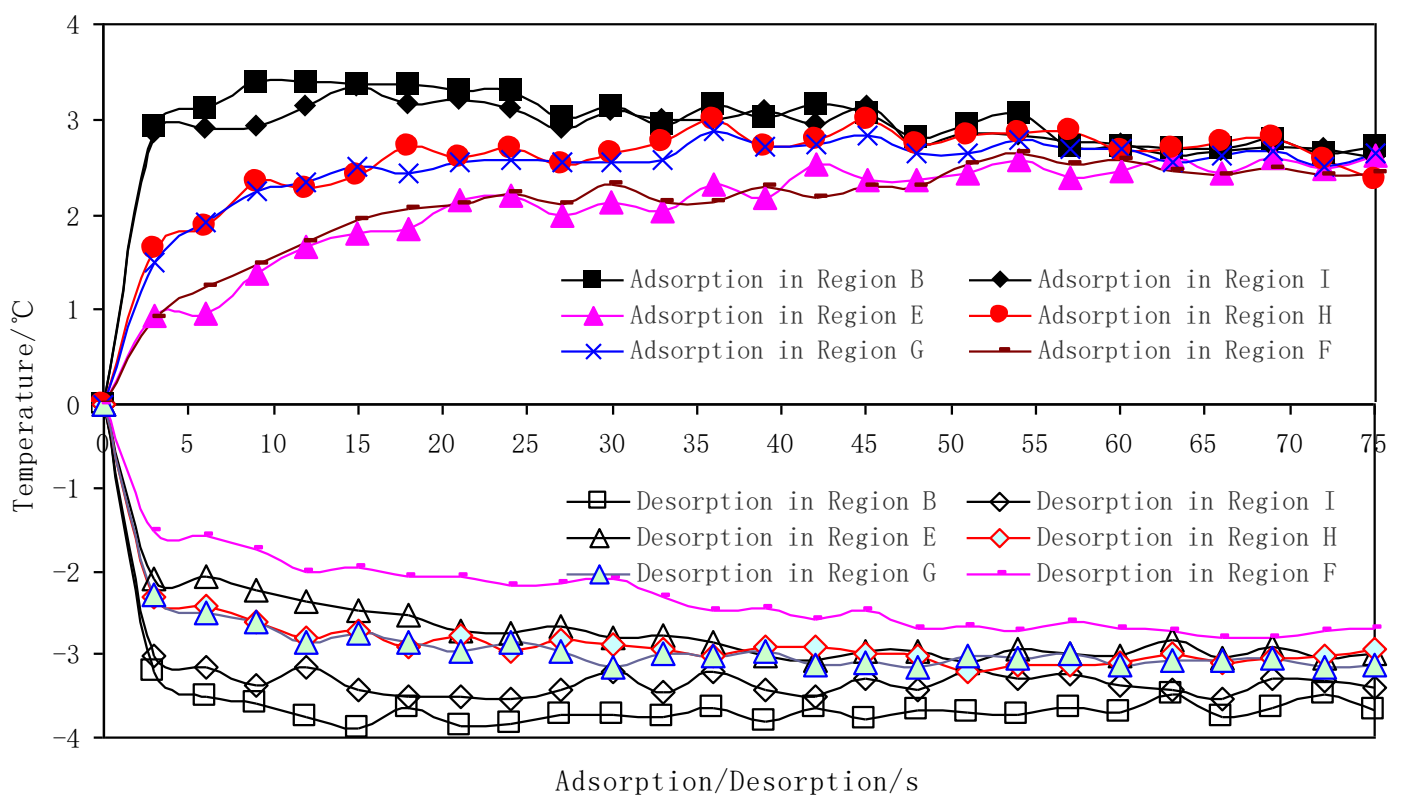

Fig. 6 Temperature change of different meso structure of coal during methane adsorption/desorption under 1.2 MPa 